\title{
Urinary Tract Obstruction and Stercoral Colitis Complicating Constipation in Geriatric Patient
}

\author{
o Osman ${ }^{1 *}$, Susmitha Dande ${ }^{2}$, Isaac Trelles ${ }^{3}$ and Odalys Frontela ${ }^{4}$ \\ ${ }^{1}$ Geriatrics Fellow, Larkin Hospital, PSC, USA \\ ${ }^{2}$ Postgraduate Subintern, Larkin Hospital PSC, USA \\ ${ }^{3}$ Geriatrics Fellowship Program Director, Larkin Hospital, PSC, USA \\ ${ }^{4}$ Internal Medicine Residency Program Director, Larkin Hospital, PSC, USA \\ *Corresponding Author: O Osman, Geriatrics Fellow, Larkin Hospital, PSC, USA.
}

Received: February 04, 2021

Published: February 15, 2021

(C) All rights are reserved by 0 Osman., et al.

\begin{abstract}
Constipation is common among geriatric patients. A prevalence of $40 \%$ has been reported which is increasing over the years $[1,2]$. Geriatric population suffer from constipation due to various reasons such as polypharmacy, endocrine disorders, electrolyte imbalance, insufficient fiber and water intake, neurological conditions and pelvic floor dysfunction in women. In this case report we present a geriatric patient with chronic untreated constipation which leads to urinary tract obstruction and a rare condition called stercoral colitis.
\end{abstract}

Keywords: Constipation; Stercoral Colitis; Urinary Tract Obstruction

\section{Introduction}

Constipation is common among geriatric patients. A prevalence of $40 \%$ has been reported which is increasing over the years $[1,2]$.

\section{Case Presentation}

95 years old female with past medical history significant for hypertension, diabetes and trigeminal neuralgia who presented to the emergency department (ED) at Larkin Community Hospital (LCH) PSC with constipations for 7 days and inability to urinate over the last 24 hours prior to presentation. Patient stated that her last bowel movement was about a week prior to admission. Patient denied nausea, vomiting, or spontaneous abdominal pain. On arrival, the ED staff noted lower abdominal mass that was decompressed after placement of a Foley catheter that drained 1200 $\mathrm{ml}$ of cloudy urine. Later assessment revealed resolution of the abdominal mass. Review of system was not contributing. Initial investigations showed mild hypokalemia of 3.4 and initial imag- ing showed large stool volume, dilation of the rectum with adjacent wall thickening and posterior fatty stranding consistent with stercoral colitis (Figure 1).

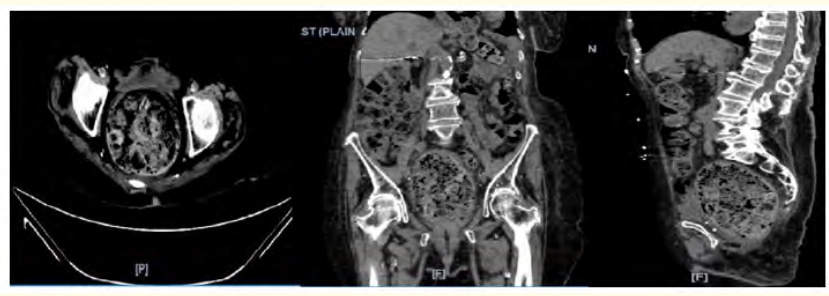

Figure 1: CT scan of abdomen and pelvis WO contrast.

\section{Discussion and Conclusion}

In the above case, our patient presented with abdominal mass which is secondary to acute urinary retention and chronic consti- 
pation After catheterization and $1200 \mathrm{ml}$ of urine drained, patient symptoms improved. Urinary bladder and rectum share a common embryological origin and innervations that have close similarities. Furthermore, the close proximity of these two organs may explain why dysfunction in one may influence the function of the other [3]. Defecation problems and lower urinary tract symptoms (LUTS) have been reported to occur together [3]. It has also been reported form prospective study in constipated elderly with concomitant lower urinary tract symptoms (LUTS) that the medical relief of constipation also significantly improves LUTS [3]. Acute urinary obstruction has been reported complicating constipation in a young adult [4]. However, few reports exist which associate acute urinary obstruction to constipation in older patients like our case. Despite of the fact that our patient was maintained on oxybutynin prior to presentation, it does not seem to help and constipation is the most likely cause of the acute urine retention.

Besides the high stool burden and fecaloma, the Computerized Tomography (CT) scan of the abdomen findings are consistent with Stercoral colitis which is a rare condition especially seen in geriatric populations [5]. Impacted fecal material in colonic segments was the main cause of Stercoral colitis (SC). Clinical and laboratory findings are not sufficient for the diagnosis of SC. Rectosigmoid colon was the most frequently involved segment [5]. CT findings of stercoral colitis include thickening bowel wall and dilation, mucosal discontinuity, pericolonic stranding, free air and free fluid. The mortality was related to the length of the affected Colon. There was a statistically significant relationship between the length of the affected colon segment $>40 \mathrm{~cm}$ and mortality $(\mathrm{P}=0.010)$ [5].

The management of Stercoral colitis requires early diagnosis with CT imaging followed by prompt aggressive bowel cleansing and manual disimpaction, which may reduce pressure and decrease the risk of ulceration. In our case stool softeners and enemas were sufficient to resolve the impaction and the fecaloma. The best approach to prevent stercoral colitis is to prevent constipation, which is present in approximately $60 \%$ of patients with fecal impaction [6].

\section{Bibliography}

1. Gustafsson M., et al. "Constipation and laxative use among people living in nursing homes in 2007 and 2013". BMC Geriatrics 19.1 (2019): 38.
2. Gonzales MJ and Widera E. "Nausea and other nonpain symptoms in long-term care". Clinics in Geriatric Medicine 27 (2011): 213.

3. Averbeck Marcio A and Madersbacher Helmut. "Constipation and LUTS: how do they affect each other". International Brazilian Journal of Urology 37.1 (2011): 16-28.

4. Smith AJ and Blackburn P. "An Unusual Cause of Acute Urinary Retention". Clinical Practice and Cases in Emergency Medicine 2.2 (2018): 171-172.

5. Morano C and Sharman T. "Stercoral Colitis”. In: StatPearls [Internet]. Treasure Island (FL): StatPearls Publishing (2020).

6. Mohamed Aly MD., et al. "Early Diagnosis and Treatment of Stercoral Colitis With an Aggressive Bowel Regimen". American Journal of Gastroenterology 109 (2014): S399.

\section{Assets from publication with us}

- Prompt Acknowledgement after receiving the article

- Thorough Double blinded peer review

- Rapid Publication

- Issue of Publication Certificate

- High visibility of your Published work

Website: www.actascientific.com/

Submit Article: www.actascientific.com/submission.php Email us: editor@actascientific.com

Contact us: +919182824667 